\title{
Analysis and Theoretical Evaluation of Iraqi High Voltage Power Transmission Line
}

\author{
A. A. Salman ${ }^{1}$, H. T. Ziboon ${ }^{2}$ \\ ${ }^{1,2}$ Department of Electrical Engineering, University of Technology, Baghdad, Iraq \\ abdkadazeez@gmail.com, hadiziboon@gmail.com
}

\begin{abstract}
The Powerline Communications (PLC) technology allows data transmission through electrical wires. Thus the electrical wiring will represent a data transmission channel conformable to the physical layer of the open system interconnection (OSI) model. In this work, the specifications of the Iraqi electrical network were used to model a high-voltage transmission line using a transmission (ABCD) matrix and use it as a communication channel for transmitting data within a narrow band (30-500). The transfer function of the suggested model was derived and its performance analysis was performed to evaluate the Line length effect, load impedance $Z_{L}$ and the source impedance $Z_{S}$ on the channel frequency response. This analysis was done with the help of Matlab16a simulator program.
\end{abstract}

Index Terms - High voltage, Iraqi power network, transmission line model.

\section{INTRODUCTION}

Traditional PLC provides real-time communication for safeguarding the High Voltage (HV) transmission line [1, 2]. Recent PLC now offers high-speed data transmission and also economical as it makes use of the communication system already present and the cost mainly associated is only with the terminal equipment. More about this subject has been found in references [3-6]. Analog PLC (aPLC) is commonly used for transmission of voice and low data rate. aPLC proves to be useful for low bit rate data transmission while using it with SCADA and RTU. As aPLC has a disadvantage for transmitting a low bit rate, a reliable digital PLC (dPLC) can be used for high bit rate data transmission [7]. The following proposed PLC system according to the specifications of high voltage $132 \mathrm{KV}$ of Iraqi overhead transmission line are analyzed and designed. The performance evaluation of the proposed model is given in this work to evaluate the effects of the length of the line, load resistance $Z_{L}$ and the source resistance $Z_{S}$ on the frequency response of the channel. This will be done by using the Simulation program for Matlab16a. The second section explains the high voltage PLC model. The third section discussed the model parameters for the transmission line. The fourth section deals with power channel model. Simulation results and conclusions are given in section 5 and 6 respectively.

\section{HIGH VOLTAGE (HV) PLC MODEL}

According to the Iraqi power grid, a high voltage power line $(132 \mathrm{kV})$ has been modeled as a communication channel for narrowband $(28-500 \mathrm{kHz})$ data transmission [8]. A signal from PLC travels from the transmitter, coupling devices over the power line to the receiver. A similar path is provided for the bidirectional path. Three different parts of the PLC system are shown in Fig. These parts are terminating system, coupling device and transmission line [9]. The terminating system contains a transmitter, receiver, and 
protective relays. Coupling devices include line tuner, a coupling capacitor, and line trap. The function of the coupling device is to connect the terminals to selected points on the power line. The transmission line is a medium for transmission of carrier energy among the terminals in PLC band of frequencies. Depending on the number of functions to be performed, the transmitters at the terminals can be one or more.

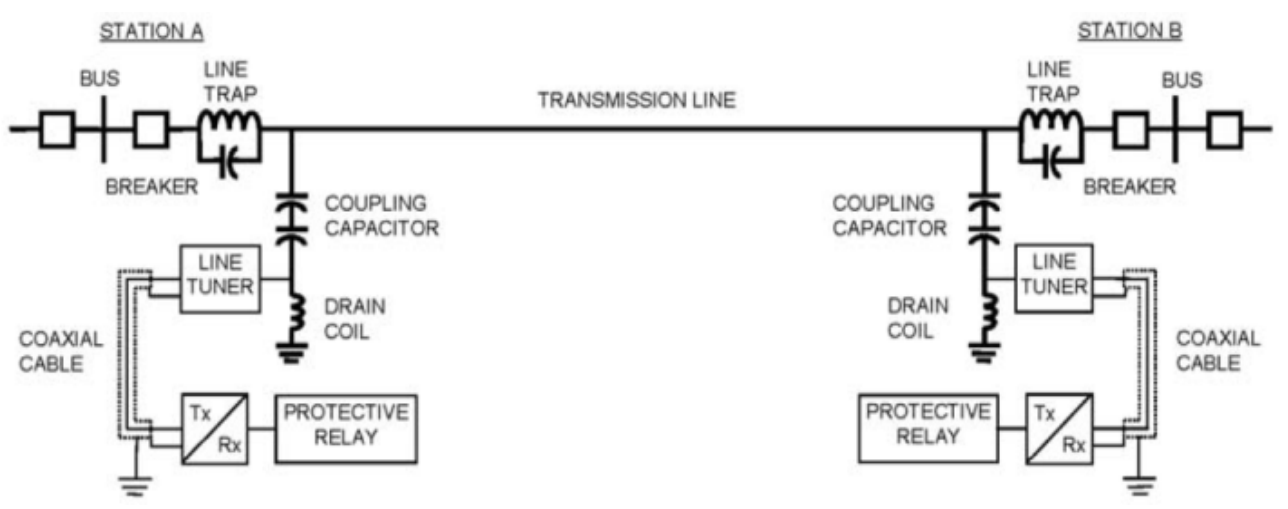

FIG. 1. PLC SYSTEM [9].

The carrier energy is coupled with the transmission line with the help of a coupling capacitor. This is the physical link to a transmission line having a high impedance for power frequency and low impedance to the carrier frequency. The drain coil, part of coupling capacitor (or added inline tuner) offers low impedance path to ground for power frequency and high impedance for carrier frequency. The impedance matching between the terminating systems and the transmission line is offered by line tuner to provide resonant tuning with a coupling capacitor. To minimize the loss of carrier energy line trap is inserted in power lines; it also prevents the external faults from shorting the carrier signal. The transmission line provides the path to PLC energy.

\section{DERIVATION OF MODEL PARAMETERS FOR TRANSMISSION LINE}

For increasing the tensile strength, the aluminum conductor is reinforced into galvanized steel wires. The obtained composite conductor is steel Cored aluminum and termed as ACSR (Aluminum Cored Steel Reinforced). The ACSR is shown in Fig. 2 [10].

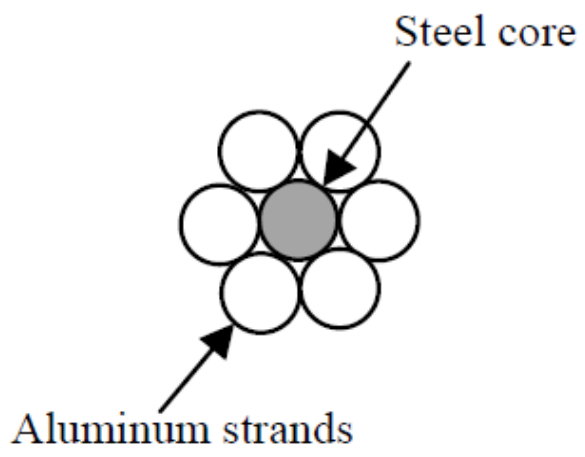

FIG. 2. ALUMINUM CONDUCTOR STEEL REINFORCED (ACSR) STRANDING. 


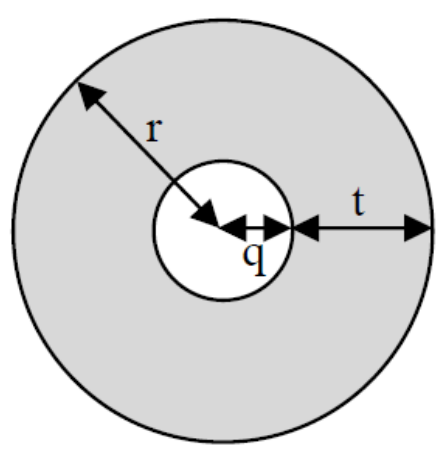

\section{FIG. 3. HOLLOW CONDUCTOR MODEL FOR ACSR CONDUCTOR.}

Due to the impact of the skin, most of the current will pass through the aluminum wire. It can be assumed that there is a hole in the middle of the aluminum conductor, as shown in Fig. 3 [10].

\section{A. Line resistance}

From (Fig. 3), the value of both $\mathrm{q}$ and $\mathrm{t}$ can be calculated as follows:

$$
\begin{aligned}
& q=r_{C} \sqrt{n_{C}} \\
& t=-q+\sqrt{q^{2}+n_{S} \times r_{S}^{2}}
\end{aligned}
$$

where, $r_{C}$ is the radius of inside steel interline, $n_{C}$ is number oa $\mathrm{f}$ inside steel interlining, $r_{S}$ is the radius of aluminum wire and $n_{S}$ is number of alumina a um wires,

So, the resistance of skin off the act of ACSR can be given as follows [11, 12]:

$$
\begin{aligned}
& R_{s e}=\frac{R_{0} a_{1} t(q+r)}{2 r \sqrt{2}}(\Omega / \mathrm{m}) \\
& R_{0}=\frac{\rho}{\pi\left(r^{2}-q^{2}\right)}(\Omega) \\
& a_{1}=\sqrt{\frac{2 \pi f \mu_{a}}{\rho}}\left(m^{-1}\right)
\end{aligned}
$$

where $\rho$ and $\mu_{0}$ is the conductance and permeability of aluminum wire respectively.

\section{B. Line inductance}

1) Single phase line

The inductance of a conductor for single phase line is given by [12]

$$
L=2 * 10^{-7} \ln \left(D_{m} / D_{s}\right) \text { henry/meter }
$$

where, $D_{s}=0.7788 \mathrm{r}=$ Geometric Mean Radius $(\mathrm{GMR})$ and $D_{m}=$ the space between the conductors $=d$.

2) Three phase line

a) Single circuit

The inductance per phase is given by [12]

$$
L=2 * 10^{-7} \ln \left(D_{m} / D_{s}\right) \text { henry/meter }
$$

Where, $D_{s}=0.7788 \mathrm{r}=$ Geometric Mean Radius $(\mathrm{GMR})$ and 
$D_{m}=\sqrt[3]{d_{1} d_{2} d_{3}}$, where $d_{1}, d_{2}, d_{3}$ are spacing between the conductors.

b) Double Circuit

The inductance per phase is as given in Eq.n (7) but with [12]:

$$
D_{s}=\sqrt[3]{D_{s 1} D_{s 2} D_{s 3}} \text { and } D_{m}=\sqrt[3]{D_{A B} D_{B C} D_{C A}}
$$

here, $D_{s 1}, D_{s 2}$, and $D_{s 3}$ illustrate the self-G.M.D. for each phase collection in placement 1, 2 and 3 respectively, and $D_{A B}, D_{B C}$, and $D_{C A}$ illustrate the mutual G.M.D. between phases A and B, B and $\mathrm{C}$ and $\mathrm{C}$ and $\mathrm{A}$ respectively. Inductive reactance is given by:

$$
X_{L}=2 \pi f L
$$

\section{Line capacitance}

1) Single phase two-wire line

Capacitance of single-phase two-wire line is given by [12]

$$
C_{A B}=\frac{\pi \varepsilon_{0}}{\log _{e} \frac{d}{r}} F / m
$$

and the capacitance to neutral

$$
C_{N}=\frac{2 \pi \varepsilon_{0}}{\log _{e} \frac{d}{r}} F / m
$$

where $\mathrm{C}_{\mathrm{N}}=\mathrm{C}_{\mathrm{AN}}=\mathrm{C}_{\mathrm{BN}}=2 \mathrm{C}_{\mathrm{AB}}$

2) The capacitance of phase to phase overhead line

The value of capacitance of phase to phase overhead line is calculated in two cases [12]:

a) Symmetrical spacing

$$
C_{N}=\frac{2 \pi \varepsilon_{0}}{\log _{e^{\frac{d}{r}}}} F / m
$$

b) Unsymmetrical spacing

$$
C=\frac{2 \pi \varepsilon_{0}}{\log _{e} \frac{\sqrt[3]{d_{1} d_{2} d_{3}}}{r}} F / m
$$

3) Susceptance

Capacitive reactance :

$$
X_{C}=\frac{1}{2 \pi f C}
$$

Susceptance is given by

$$
\beta=\frac{1}{X_{C}} S / m
$$

ToThe total series impedance of lithe ne

$$
Z=R+j X_{L} \Omega
$$

Total series admittance of line

$$
Y=G+j \beta S
$$

4) Characteristic impedance

$$
Z_{C}=\sqrt{\frac{R+j \omega \mathrm{L}}{G+j \omega \mathrm{C}}}
$$


5) Propagation constant

$$
\gamma=\sqrt{\left(R+j X_{L}\right)(G+j \beta)}
$$

\section{POWER LINE CHANNEL MODEL}

For transmitting the information on a channel, it becomes most important to model and characterize different parameters of the communication channel. This helps in understanding the possible domains of the transfer function, symmetry, the impulse response of the channel under different conditions to which channel is subjected during data transmission [13]. In this work, the modeling of PLC channel has been done using a twoport model using $A B C D$ parameters, where the branching parameters are needed to be taken care during modeling. Fig. 4 shows the transmission matrix of a two-port network.

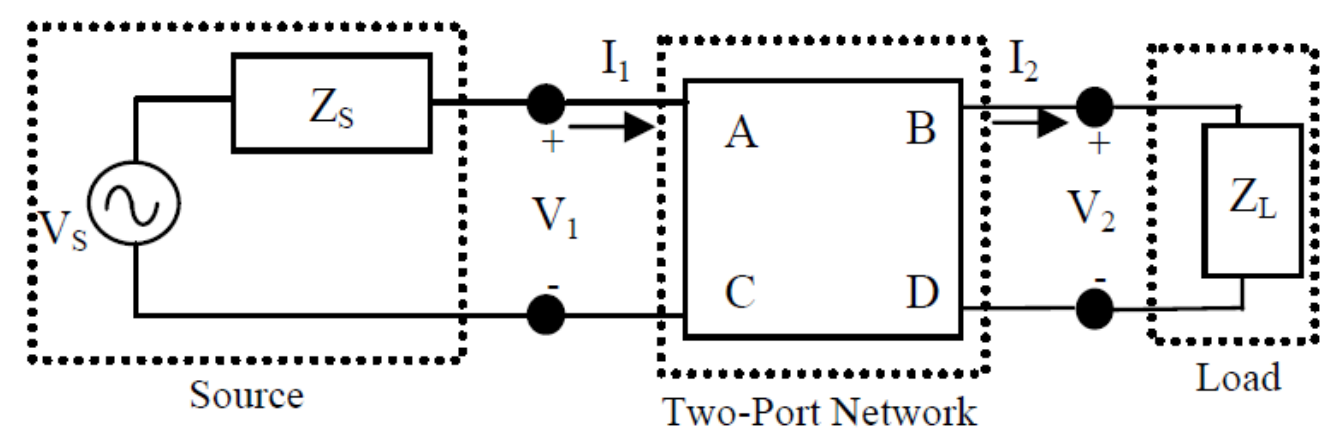

FIG. 4.TRANSMISSION MATRIX OF TWO PORT NETWORK.

The relation between transmitter parameters $\left(V_{1}\right.$ and $\left.I_{1}\right)$ and receiver parameters $\left(V_{2}\right.$ and $\left.I_{2}\right)$ using $\mathrm{ABCD}$ matthe rix is as follows $[10,13-16]$ :

$$
\left[\begin{array}{l}
V_{1} \\
I_{1}
\end{array}\right]=\left[\begin{array}{ll}
A & B \\
C & D
\end{array}\right]\left[\begin{array}{l}
V_{2} \\
I_{2}
\end{array}\right]=\left[\begin{array}{cc}
\cosh (\gamma l) & Z_{C} \sinh (\gamma l) \\
\frac{1}{z_{C}} \sinh (\gamma l) & \cosh (\gamma l)
\end{array}\right]\left[\begin{array}{l}
V_{2} \\
I_{2}
\end{array}\right]
$$

where $l$ is the length of the transmission line.

Thus, the transfer function of the power line channel model shown in Fig. 4 can be given as [15$18]$.

$$
H=\frac{Z_{L}}{A Z_{L}+B+C Z_{L} Z_{S}+D Z_{S}}
$$

The power line network especially distribution network is not as simple as shown in Fig. 4, rather it contains bridge tapes of different cable types and different cable lengths so that a power line network can be made up of several sections $[10,15]$. The transfer function of these several sections of power line network can be calculated as in Eq.n (20). And the ABCD matrix can be calculated by multiplying $\mathrm{ABCD}$ matrices with different sections to obtain the overall $\mathrm{ABCD}$ matrix.

Fig. 5 shows the transmission line with one bridge tap which can be replaced with an equivalent circuit as shown in (Fig. 6) [10], where $Z_{e q}$ can be calculated as:

$$
Z_{e q}=Z_{c b r} \frac{Z_{b r}+Z_{c b r} \tanh \left(\gamma_{b r} l_{b r}\right)}{Z_{c b r}+Z_{b r} \tanh \left(\gamma_{b r} l_{b r}\right)}
$$

where, $Z_{c b r}$ is characteristic impedance and $\gamma_{b r}$ is the propagation constant of the bridge tap. 
(Fig? 6) can be separated into four subcircuits such as $\phi_{0}, \phi_{1}, \phi_{2}, \phi_{3}$. The ABCD matrix for these transfer function is calculated as [10]:

$$
\begin{gathered}
\phi_{0}=\left[\begin{array}{ll}
1 & Z \\
0 & 1
\end{array}\right] \\
\phi_{1}=\left[\begin{array}{cc}
\cosh \left(\gamma_{1} d_{1}\right) & Z_{c l 1} \sinh \left(\gamma_{1} d_{1}\right) \\
\frac{1}{z_{c l 1}} \sinh \left(\gamma_{1} d_{1}\right) & \cosh \left(\gamma_{1} d_{1}\right)
\end{array}\right]
\end{gathered}
$$

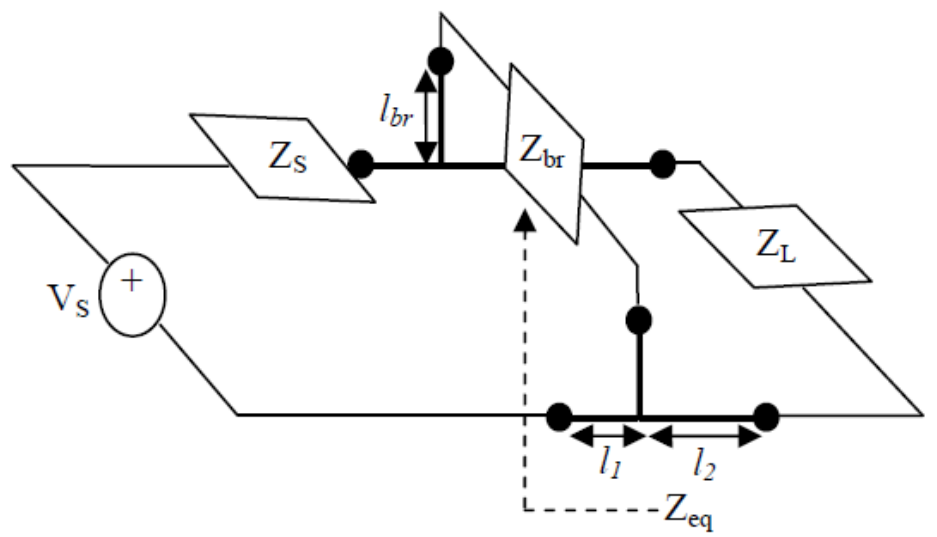

FIG. 5. TRANSMISSION LINE WITH ONE BRIDGE TAPS CONNECTION.

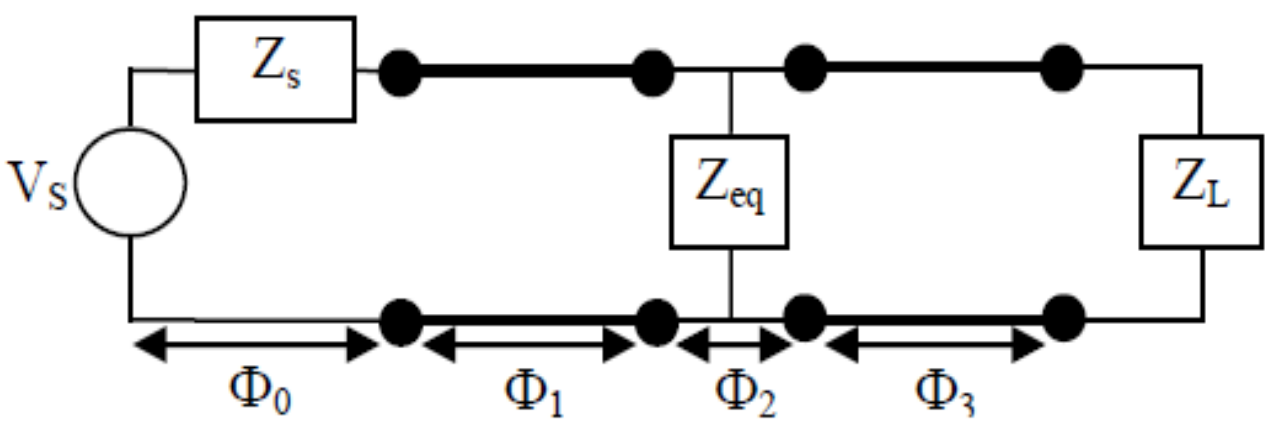

FIG. 6. EQUIVALENT NETWORK FOR ONE BRIDGE TAP CONNECTION

$$
\begin{gathered}
\phi_{2}=\left[\begin{array}{ll}
1 & 0 \\
\frac{1}{z_{e q}} & 1
\end{array}\right] \\
\phi_{3}=\left[\begin{array}{cc}
\cosh \left(\gamma_{2} d_{2}\right) & Z_{c l 2} \sinh \left(\gamma_{2} d_{2}\right) \\
\frac{1}{z_{c l 1}} \sinh \left(\gamma_{2} d_{2}\right) & \cosh \left(\gamma_{2} d_{2}\right)
\end{array}\right] \\
{\left[\begin{array}{ll}
A & B \\
C & D
\end{array}\right]=\prod_{i=0}^{3} \phi_{i=} \phi_{0} \phi_{1} \phi_{2} \phi_{3}}
\end{gathered}
$$

where, $Z_{c l 1}, \gamma_{1}$ is the characteristic impedance and propagation constant of second sub circuit respectively and $Z_{c l 2}$, and $\gamma_{2}$ is the characteristic impedance and propagation constant of fourth sub circuit respectively. The value of the transfer function can be calculated with the obtained $\mathrm{ABCD}$ matrix. But with the increase in bridge taps, the complexity increases and the formula for calculating ABCD matrices increase in size [10]. Several works have been achieved on modeling the power line channel in different voltage levels such as $[19,20]$. 


\section{SIMULATION RESULTS}

The modeling process will be carried out on a high voltage overhead transmission line 132KV which has geometry type of a double circuit. In this work, the specifications of the transmission line (132 KV) connecting the West Karbala station with the Al-Akhaydir station have been adopted. This overhead power line is characterized by the use aluminum cored steel reinforced (ACSR) wire type with the code word (Teal) and conductor type (T). Table 3.1 shows the physical dimensions and parameter values of this overhead power line according to the Iraqi network specifications.

The results of the power line channel model are obtained by changing loading conditions and different cable length. All cables used in modeling are assumed to have R, L, C and G parameters with constant values for all graphs. All calculations for channel elements were performed using MATLAB16a to code the parameters of the channel and Eqns. (1-21).

TABLE 3.1: IRAQI TRANSMISSION LINE PARAMETERS

\begin{tabular}{|c|c|}
\hline Parameter & Values \\
\hline Total cross-sectional area & $377 \mathrm{~mm} 2$ \\
\hline Resistance & $0.097 \mathrm{Ohm} / \mathrm{Km}$ \\
\hline Inductive reactance & $0.387 \mathrm{Ohm} / \mathrm{Km}$ \\
\hline Capacitive reactance & $2.97 \mathrm{Ohm} / \mathrm{Km}$ \\
\hline Emergency rating power & 151 MVA \\
\hline Emergency rating current & $660 \mathrm{~A}$ \\
\hline Radius of inside steel interline, $r_{c}$ & $2.164 \mathrm{~mm}$ \\
\hline Radius of aluminum wire, $r_{s}$ & $3.607 \mathrm{~mm}$ \\
\hline No. of inside steel interline, $n_{c}$ & 19 \\
\hline No. of aluminum wire, $n_{s}$ & 30 \\
\hline Aluminum conductivity, $\rho$ & $3.5 \times 10^{7}$ \\
\hline permeability, $\mu_{a}$ Aluminum & $1.256665 \times 10^{-6} \mathrm{H} / \mathrm{m}$ \\
\hline Free space pemeability, $\mu_{0}$ & $4 \pi \times 10^{-7} \mathrm{H} / \mathrm{m}$ \\
\hline Permittivity of free space, $\varepsilon_{0}$ & $8.8542 \times 10-12 \mathrm{~F} / \mathrm{m}$ \\
\hline Conductor radius, $r$ & $25.248 \mathrm{~mm}$ \\
\hline $\begin{array}{l}\text { Distance between conductors, } \\
\qquad D_{A B}, D_{B C} D_{C A}\end{array}$ & $3.85 \mathrm{~m}, 3.85 \mathrm{~m}$ and $7.7 \mathrm{~m}$ \\
\hline Distance between two sides of tower & $6.5 \mathrm{~m}$ \\
\hline Length of conductor, l & Up to $90 \mathrm{Km}$ \\
\hline Frequency range, $f$ & Up to $500 \mathrm{kHz}$ \\
\hline
\end{tabular}

\section{A. Flowchart}

The flow chart of the simulation process is depicted in Fig. 7. This flow chart simply shows how transmission line parameter values are included manually to the code and calculating the values of $\mathrm{R}$, $\mathrm{L}, \mathrm{C}, \mathrm{Z}_{\mathrm{C}}$ and $Y$. Then the values of the $\mathrm{ABCD}$ matrix components are calculated. Finally, the response graph is obtained by plotting the transfer function of the resulting model, as shown in Fig. 8. 


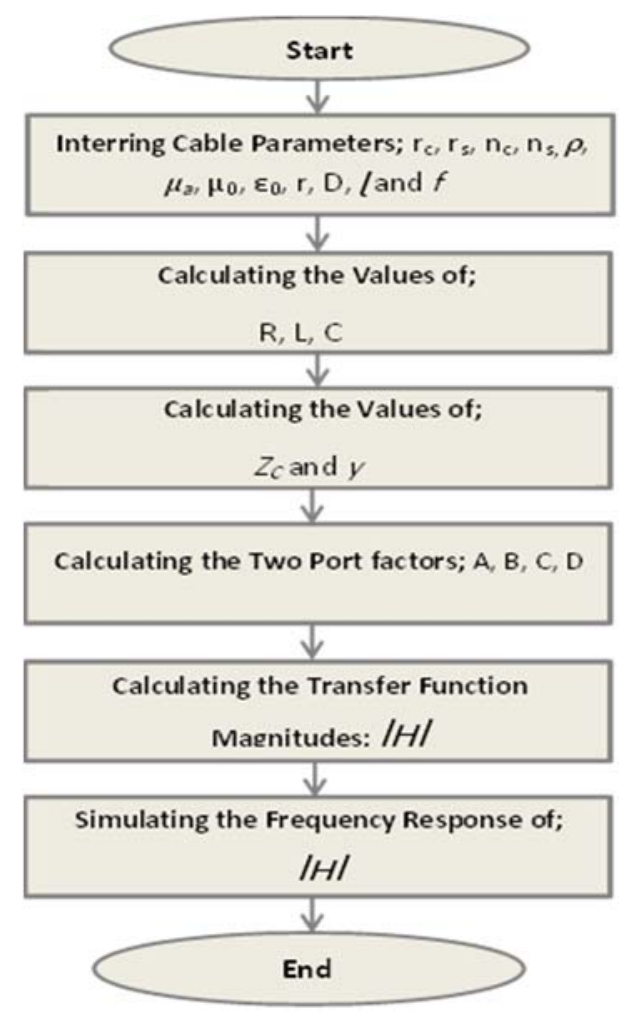

FIG. 7.FLOW CHART FOR SIMULATION PROGRAM.

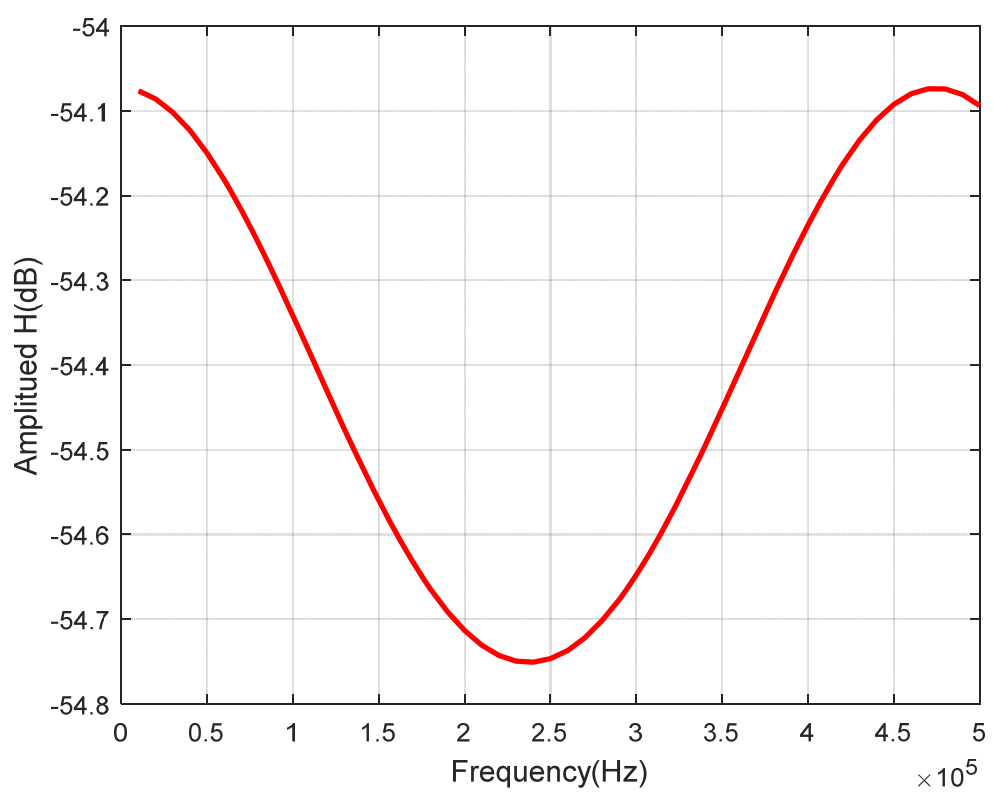

FIG. 8. CHANNEL RESPONSE FOR TRANSMISSION LINE MODEL OF LENGTH $12 \mathrm{KM}, \boldsymbol{Z}_{L}=75 \Omega$ AND $\boldsymbol{Z}_{S}=75 \Omega$.

\section{B. Mismatching effect}

1) Modeling of power line using different load matching conditions.

With no bridged tap used for this power line channel model and the length of the line is kept constant the effect of the load impedance $Z_{L}$ and source impedance are observed.

Figures 9 and 10 show that there is a slight effect of changing the values of load impedance $Z_{L}$. Evidently increasing the value of load impedance $Z_{L}$ leads to a little decrease in the attenuation value. 
The value of the decline in attenuation when the value of the load impedance changes from the lowest value to the highest allowed value does not exceed $2 \mathrm{db}$.

On the other hand, the (Figures 11and 12) show that changing the value of the source impedance $Z_{\mathrm{S}}$ has a significant negative impact on the attenuation value. (Fig.12) shows that the amount of change in the attenuation value (i.e. decreasing) due to change in the source impedance $Z_{S}$ value within the range of permissible change may reach more than $35 \mathrm{~dB}$.

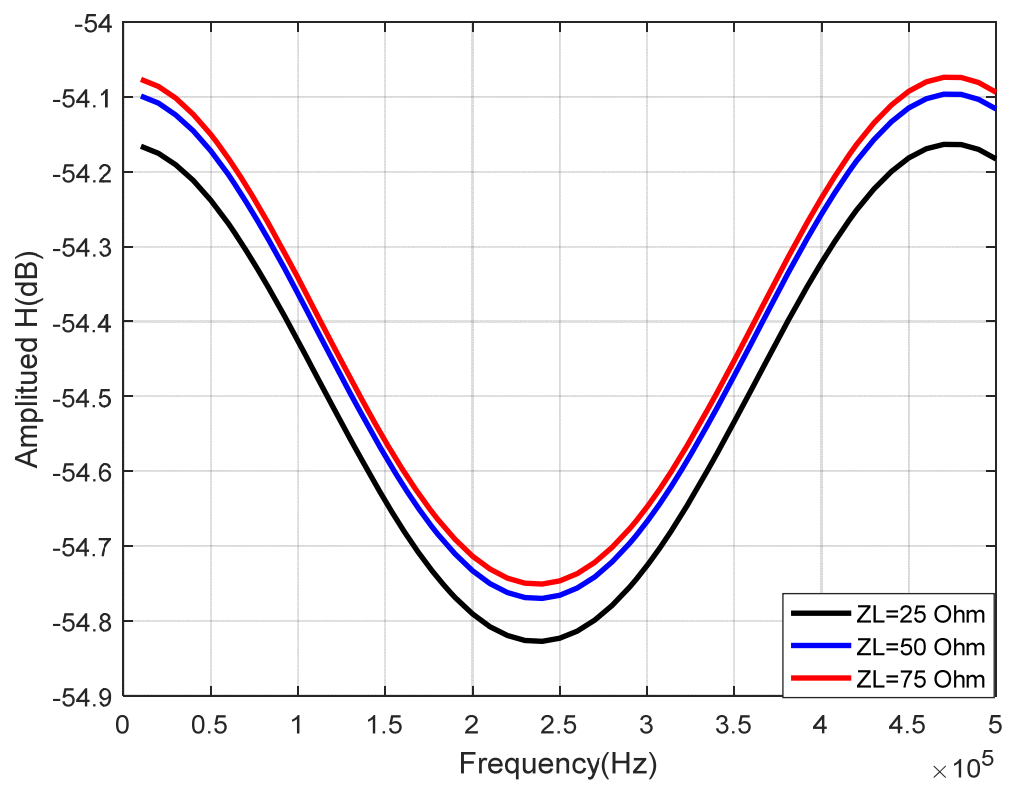

FIG. 9. TRANSFER FUNCTION FOR TRANSMISSION LINE MODEL OF LENGTH 12KM AND ZS=75 $\Omega$.

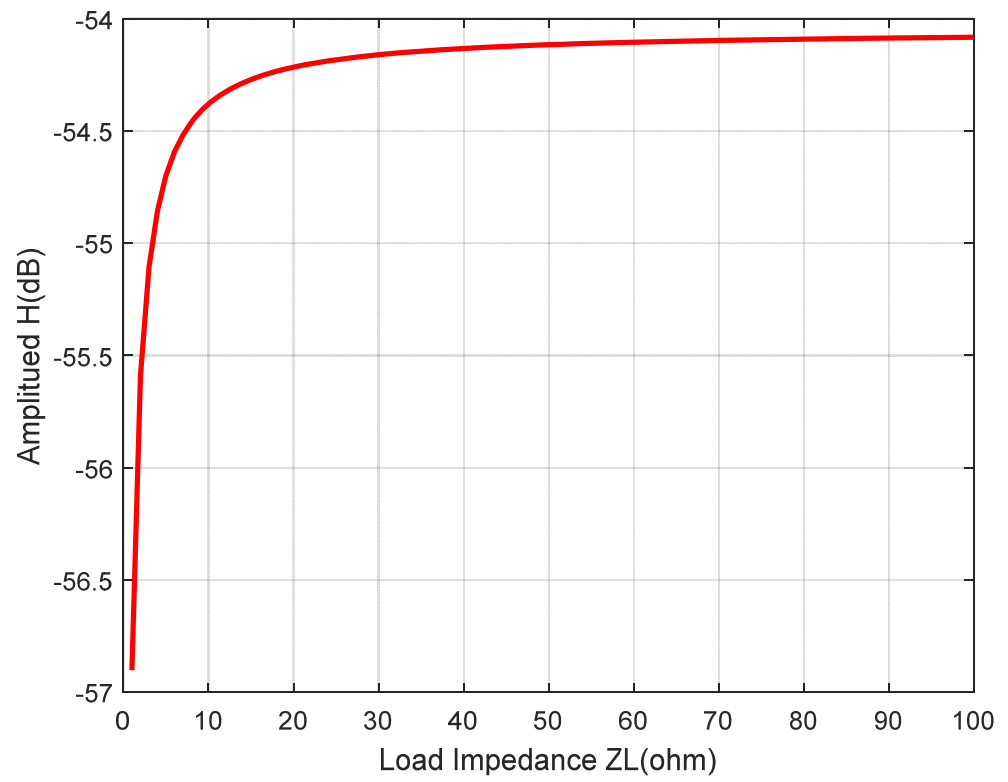

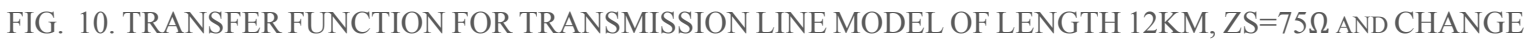
THE LOAD IMPEDANCE VALUE ZL. 


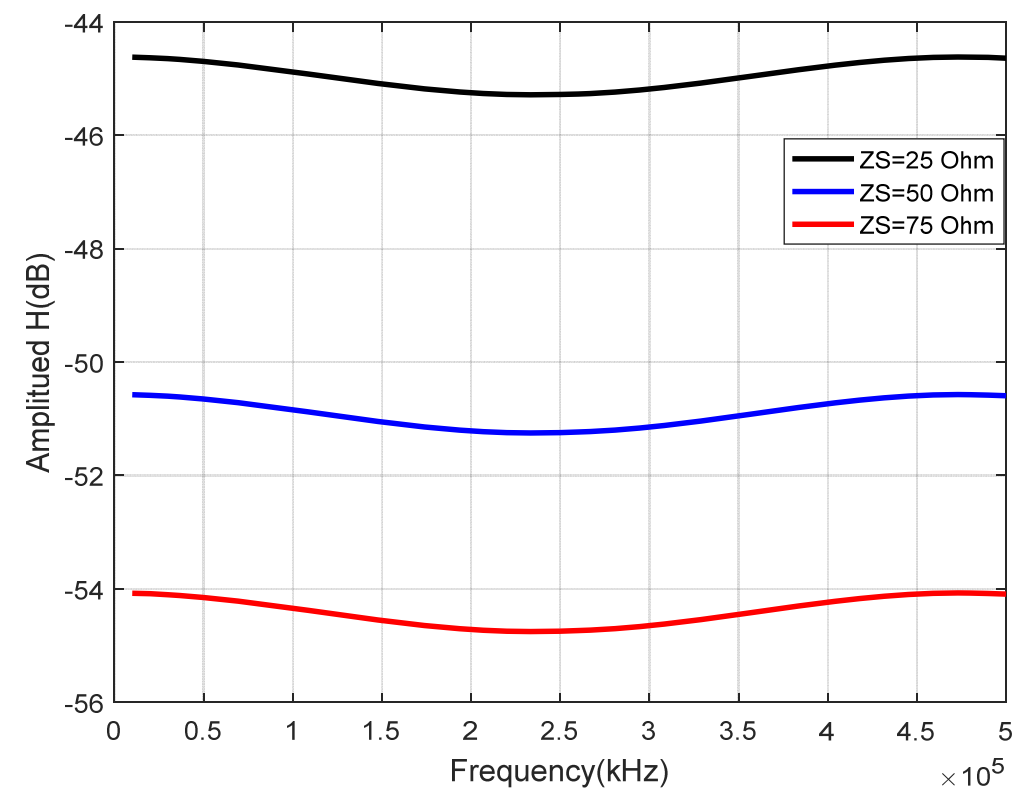

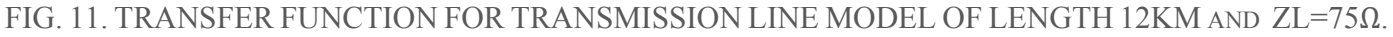

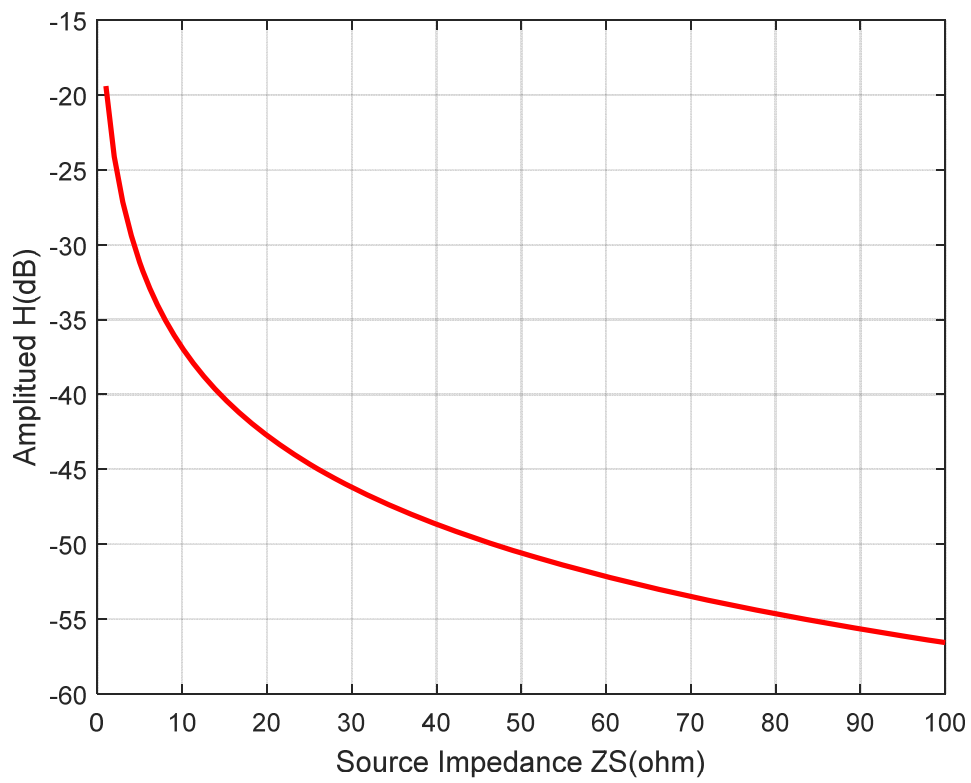

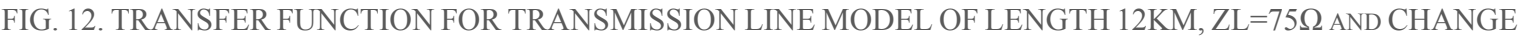
THE SOURCE IMPEDANCE VALUE ZS.

\section{2) Effect of transmission line length}

The transfer function of different transmission line lengths $(10 \mathrm{~km}, 25 \mathrm{~km}$, and $90 \mathrm{~km})$ has been tested here. The R, L, C, and G parameters as well as the loading conditions $Z_{L}=75 \Omega, Z_{S}=75 \Omega$ are kept constant and only the length of the transmission line is varied. The graph for transfer function versus the length of the transmission line is obtained for different length as follows:

Figures 13 - 15 show that with the increase in transmission line length, the attenuation of signal increases. Also, notice from the above Figures that the attenuation value decreases by about $1.2 \mathrm{~dB}$ per kilometer. This is because of the fact that, with the increase in the length of the transmission line, the signal will be exposed to the interference which will lead to attenuation. Also, the strength of the signal gets weak with the increase in the transmission line length. 
It is clear that there is a ringing (ripple) happening during the first part of the transmission line, and this is the result of the nature of the transmission line which consists of RLC basic components which form a resonant circuit. The height and width of the waves formed depends on the values of the components mentioned and also depends on the value of the frequency used. This oscillation starts to fade and decay after a certain distance (approximately $15 \mathrm{~km}$ ) and this also depends on the values of components of the transmission line (i.e. RLC).

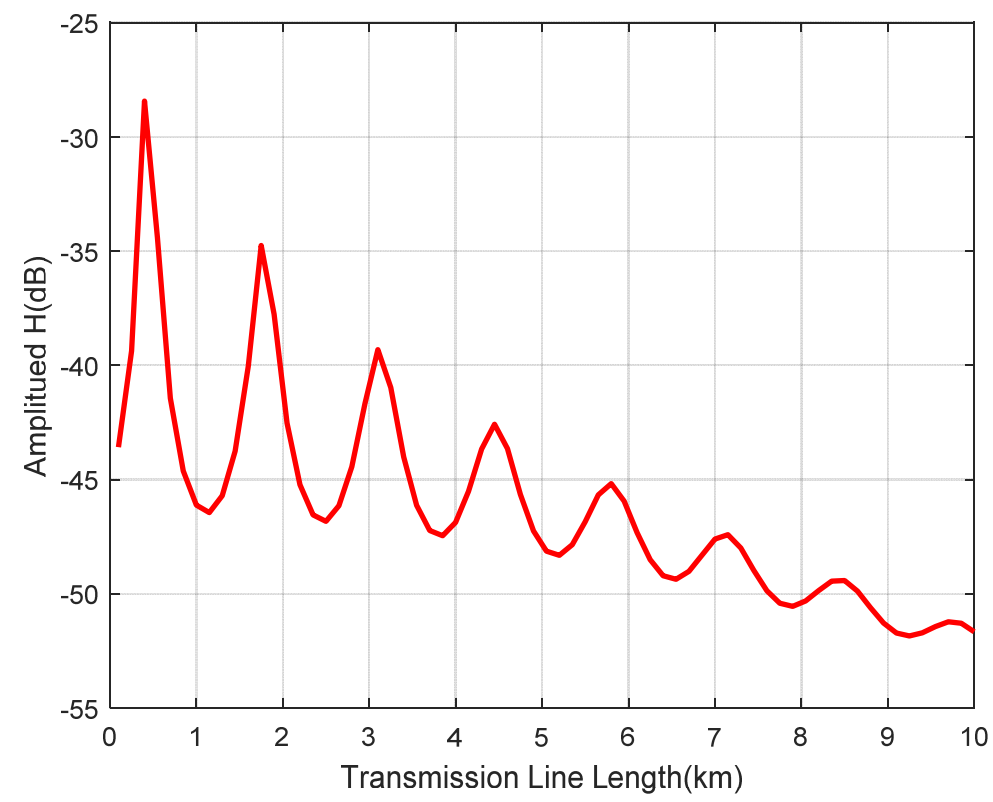

FIG. 13. TRANSFER FUNCTION MAGNITUDE WITH TRANSMISSION LINE LENGTH $10 \mathrm{KM}, \mathbf{Z}_{\mathrm{S}}=75 \Omega \mathbf{Z}_{\mathrm{L}}=75 \Omega$ AND F $=500 \mathrm{KHZ}$

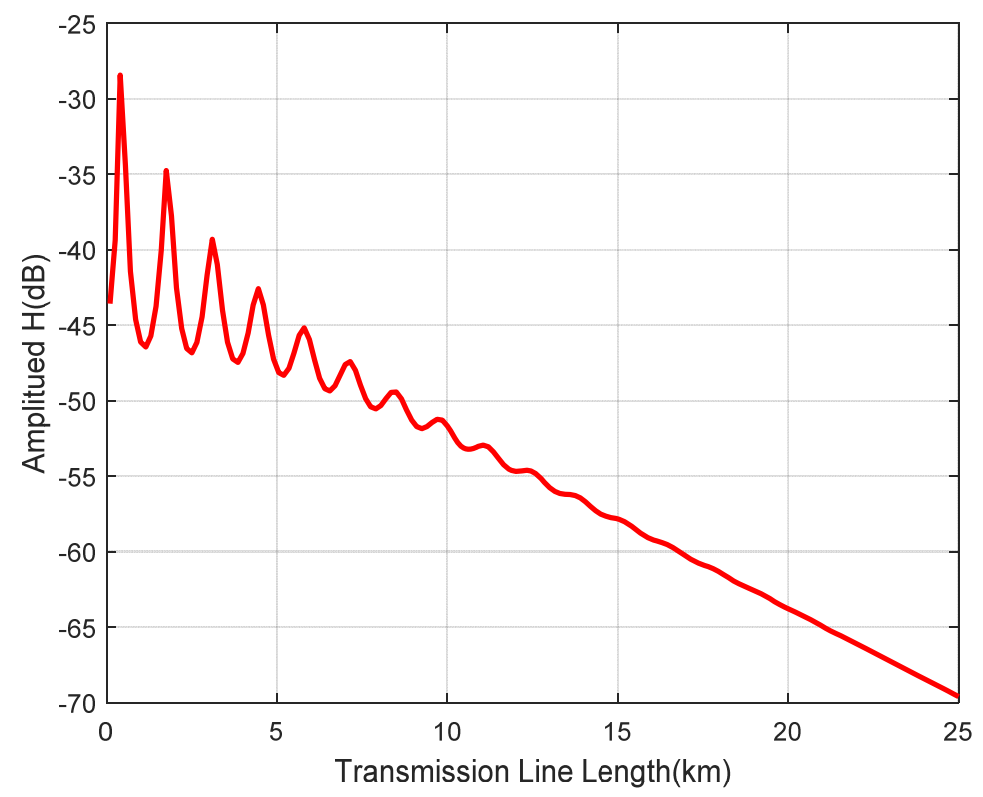

FIG. 14. TRANSFER FUNCTION MAGNITUDE WITH TRANSMISSION LINE LENGTH $25 \mathrm{KM}, \mathbf{Z}_{\mathrm{S}}=75 \Omega, \mathbf{Z}_{\mathrm{L}}=75 \Omega$ AND F $=500 \mathrm{KHZ}$ 


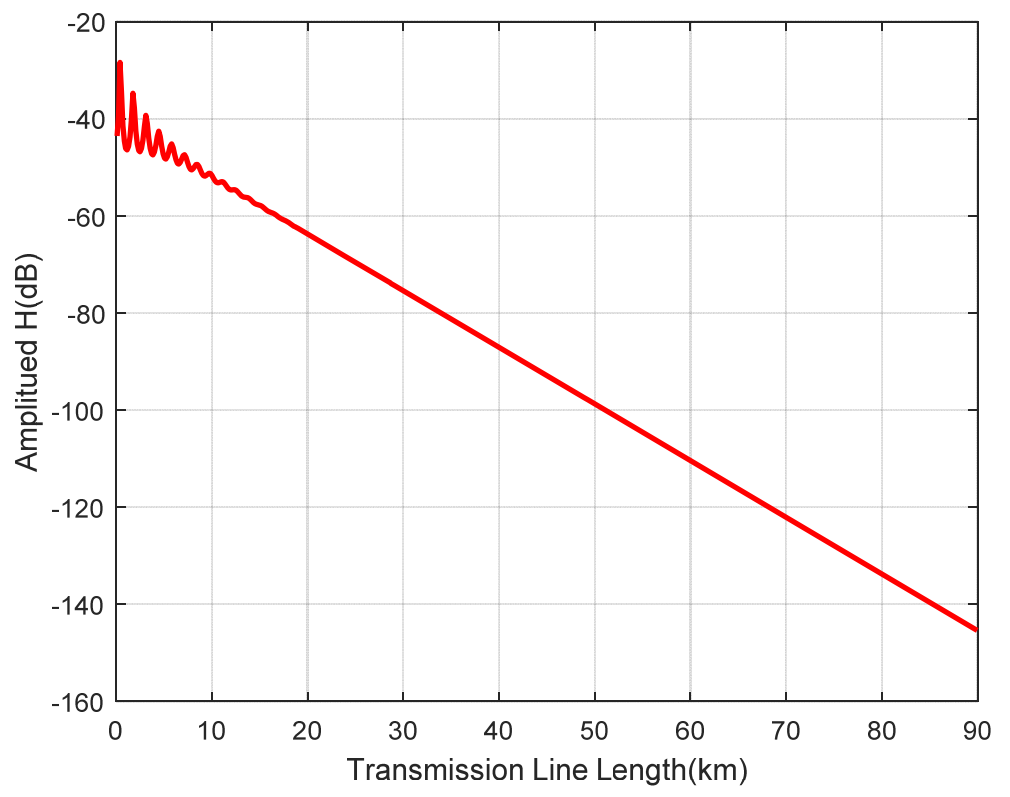

FIG. 15. TRANSFER FUNCTION MAGNITUDE WITH TRANSMISSION LINE LENGTH $90 \mathrm{KM}, \mathbf{Z}_{\mathbf{S}}=75 \Omega, \mathbf{Z}_{\mathbf{L}}=75 \Omega$ AND F= $500 \mathrm{KHZ}$.

The effect of the value of the frequency used on the specification of the ripple obtained by the transfer function response is evident in Figures 16 and17.

In the same Figures, it is possible to observe how the change in the value of the source impedance $Z_{S}$ affects the attenuation value and this is done in conjunction with the change in the frequency ripple.

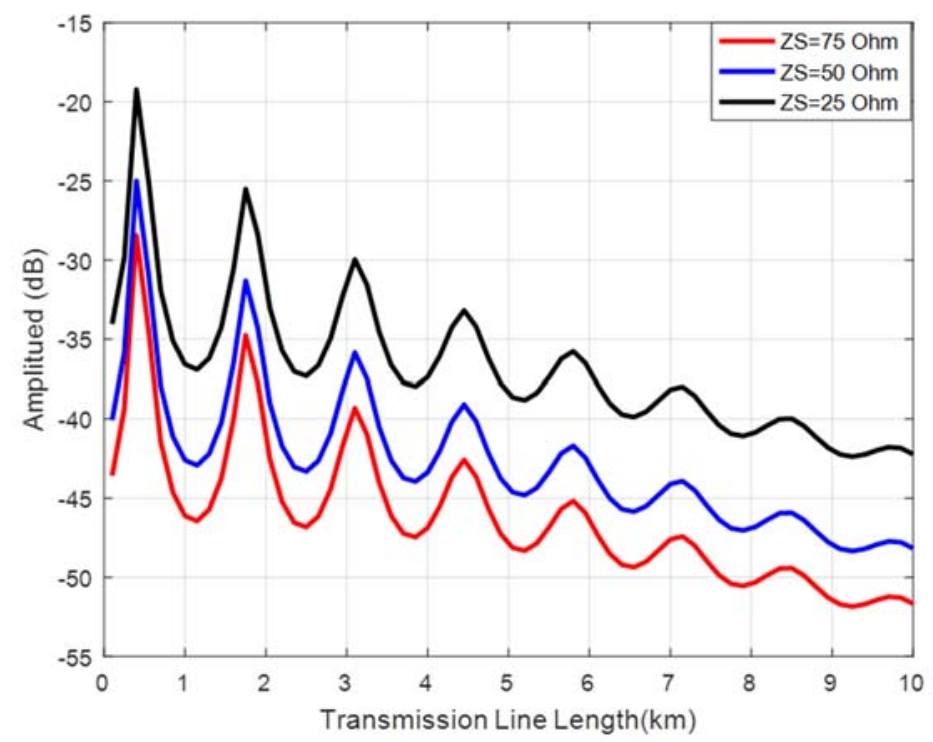

FIG. 16. TRANSFER FUNCTION MAGNITUDE WITH TRANSMISSION LINE LENGTH $10 \mathrm{KM}, \quad \mathrm{F}=500 \mathrm{KHz}, \mathbf{Z}_{\mathbf{L}}=75 \Omega$, AND DIFFERENT VALUES OF ZS. 


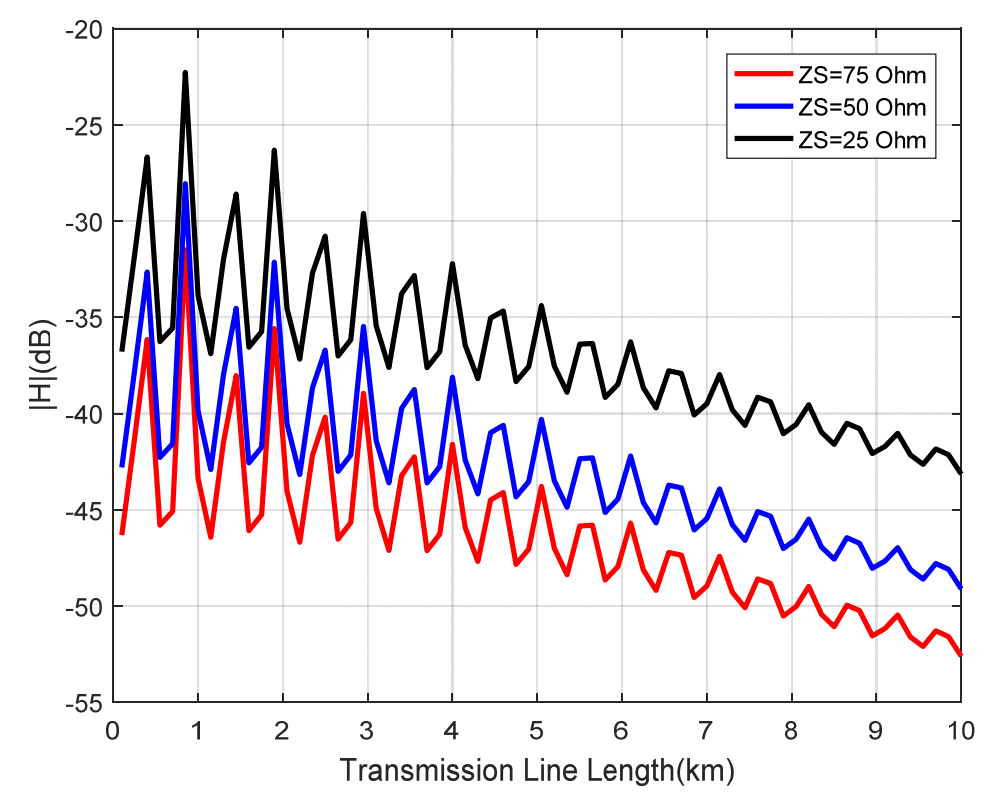

FIG. 17. TRANSFER FUNCTION MAGNITUDE WITH TRANSMISSION LINE LENGTH $10 \mathrm{KM,} \mathrm{F=30} \mathrm{KHz,} \mathrm{ZL=75} \Omega$, AND DIFFERENT VALUES OF ZS.

\section{CONCLUSIONS}

This work basically deals with the derivation of transmission line parameters. According to Iraqi power network, a high voltage (HV) $132 \mathrm{kV}$ power line is being modeled as a communication channel using $\mathrm{ABCD}$ matrix for narrowband $(30-500 \mathrm{kHz})$ data transmission. The transmission line parameters like line resistance, line capacitance, line inductance, characteristic impedance, propagation constant, etc. are derived. After which a simple model of power line channel is discussed and the transfer function and ABCD matrix are calculated. And the last part of the chapter deals with the simulation results where the flowchart for simulation is shown and simulation is done with the help of MATLAB16a. The results indicate that the attenuation increases if source impedance $Z_{S}$ is increased by keeping load impedance $Z_{\mathrm{L}}$ to be constant. Also, the effect of transmission line length is shown that with the increase in transmission line length will lead to an increase in attenuation. Finally, the ripple (resonance) in the transfer function response for transmission line and its relation to the values of the components of the transmission line and the value of the frequency used were studied.

\section{REFERENCES}

[1] M. P Sanders, PE (Quanta Technology, LLC), "A Reliable Power-Line Carrier-based Relay System", 2012 IEEE ProRelay, p 290-309, 2012.

[2] B. A. Mork, D. Ishchenko, X. Wang, A.D. Yerrabelli, R.P. Quest, C.P. Kinne, "Power Line Carrier Communications System Modeling", International Conference on Power Systems Transients (IPST’05), Canada on June 19-23, 2005.

[3] M. N.Annadate, R. A. Mulik, A. D. Patil, P. A. Palve," Industrial automation system using power line communication and Android device", International Journal of Modern Trends in Engineering and Research (IJMTER), Volume 04, Issue 3, March- 2017.

[4] N. Chiotellis and P. G. Cottis, "Simulation of a Narrowband Power Line Communications System over Medium Voltage". Appl. Sci 6, 90, 2016.

[5] S. M. Nlom, A. R. Ndjiongue, K. Ouahada, H. C. Ferreira, A. J. Han Vinck and T. Shongwe," A Simplistic Channel Model for Cascaded PLC-VLC Systems", Conference Paper, April 2017.

[6] A. Alametov, E. Halilov and T. Sayeva,"Extra high voltage transmission line operation simulation using the actual corona-loss characteristics”, Turk J Elec Eng\& Comp Sci 26: 479 - 488, 2018.

[7] M. Zajc, N. Suljanović, A. Mujčić and J. F. Tasič," High voltage power line constraints for high-speed communications", Conference Paper, June 2004. 
[8] G. Held, "Understanding Broadband over Power Line", Auerbach Publications, New York, 2001.

[9] IEEE Std 643'M-2004(R2010), " IEEE Guide for Power-Line Carrier Applications", 2011.

[10] M. Korki, N. Hosseinzadeh, H. L. Vu, T. Moazzeni, C. H. Foh, "A Channel Model for Power Line Communication in the Smart Grid", 978-1-61284-788-7/11/\$26.00@2011 IEEE, 2011.

[11] M. E. Hardy, S. Ardalan, J. B. O’Neal, Jr, “A Model for communication SignalPropagation on Three Phase Power Distribution Lines, ’IEEE Trans. Power Delivery,vol.6, no.3, pp.966-972, July 1991.

[12] V.K. Mehta and Rohit Mehta, "Principles of Power System", $4^{\text {th }}$ revised edition, S. Chand.

[13] H. Hrasnica, A. Haidine, R. Lehnert, "Broadband Powerline Communications Network Design", John Wiley \& Sons, Ltd, 2004.

[14] P. Mlynek, M. Koutny, and J. Misurec," Power line modelling for creating PLC communication system ", INTERNATIONAL JOURNAL OF COMMUNICATIONS", Issue 1, Volume 4, 2010.

[15] G. Kuma, "Mitigating EMI of Powerline Communications Using Carrier-less UWB Pulses", University of DuisburgEssen, Ph. D. thesis, September 2008.

[16] F. Lesek, S. Ladislav, B. Zdenek, " Modelling Transmission Lines for the Purpose of Data Transmission over Power Lines", Procedia Engineering 100 (2015) 1381 - 1388, 2015.

[17] Z. Hasirci, I. H. Cavdar, M. Ozturk," RLGC(f) modeling of a busbar distribution system via measured S-parameters at CENELEC and bands", Turk. J. Elec. Eng. \& Comp. Sci., 26: 489 - 500, 2018.

[18] M. Bogdanovi," Power line Communication System Modeling Based on Coded OFDM", MIPRO 2012, Croatia, 2012.

[19] A. Mujčić, N. Suljanović, M. Zajc, J. F. Tasič, "Design of channel coding methods in HV PLCcommunications",http://www.researchgate.-net/publication/265564197, 2015.

[20] S. Ezzine, F. Abdelkefi, J. P. Cances, V. Meghdadi and A. Bouallégue, "Evaluation of PLC Channel Capacity and ABER Performances for OFDM-Based Two-Hop Relaying Transmission", Wireless Communications and Mobile Computing, Volume 2017. 